\title{
A Preliminary Study of Changing Business Student Perceptions of Individual Factors in Online Versus Face-to-Face Education
}

\author{
Lynn A. Fish and Coral R. Snodgrass
}

Professors of Management, Canisius College, 2001 Main Street, Buffalo, NY

Corresponding Author: fishl@canisius.edu; (716)888-2642

\begin{abstract}
Over 6 years ago at an AACSB Jesuit, Catholic University with a strong focus on teaching, business student perceptions regarding online versus face-to-face (FTF) courses were surveyed and results indicated that students prefer face-to-face classes. Since research indicates that student perceptions change over time, this study evaluates whether for this population, perceptions changed. In this paper student factors, such as motivation, discipline, selfdirected, independence, schedule flexibility, time investment, cost investment, happiness and appropriateness of online education, are presented. This research has implications for instructors and administrators.
\end{abstract}

Keywords: Individual Perceptual Changes, Online, Face-to-face 
DOI: https://dx.doi.org/10.15239/j.brcacadje.2020.08.01.ja03

\section{LITERATURE REVIEW: STUDENT CHARACTERISTICS}

Often, administrators perceive face-to-face (FTF) and online education as equivalent (Allen \& Seamen, 2013). Assuming that administrators are correct than students should be indifferent to all educational factors. However, prior research on student perceptions are mixed and do not always show this indifference. Results at a teaching university clearly demonstrate that students preferred FTF education over online education for most factors surveyed (Fish \& Snodgrass, 2014, 2015, 2016). Other researchers found similar results (Platt, Raile \& Yu, 2014). Researchers also found that student perceptions to online education have changed over time (e.g. Allen \& Seaman, 2013; Benbunan-Fich \& Hiltz, 2003; Perreault, Waldman, Alexander \& Zhao, 2008; Tanner, Noser, and Langford, 2003; Tanner, Noser, Fuselier \& Totaro, 2004-1; 2004-2; Tanner, Noser, Totaro $\&$ Birch, 2006; Tanner et al., 2009). Differences between cultures exist as research at the turn of the century indicated differences between Australians and Asian students in student perceptions (Smith \& Smith, 1999; Ramburuth \& McCormick, 2001); however, a more recent study found no significant differences existed on many factors for these groups (Chew \& Yee, 2015). Another researcher reported changes in Chinese students' learning strategies and motivation after an online collaborative experience towards a social-constructivist learning approach (Zhu et al., 2009). Another researcher noted that studies into instructor and student perceptions will continue to evolve as technology evolves (Richardson, Besser, Koehler, Lim. \& Strait, 2016).

In our original literature review, two streams of literature emerged: studies that concentrate on students characteristics and studies that concentrate on program characteristics (Fish \& Snodgrass, 2014). In this research, we continue to explore student perceptual changes for students 
at the same University as 6 years ago and focus on the individual student characteristics.

In the original 2012 study, significant differences in students perceptions between online and FTF students existed for motivation, self-directed, independence, schedule flexibility, cost investment, and happiness (Fish $\&$ Snodgrass, 2014). In general, both groups were motivated and preferred the self-directed nature and independence of the FTF classroom. They also felt that FTF education cost more than online education. The FTF students were very happy in the FTF environment, while online students were more indifferent. Both groups felt that online education offered more schedule flexibility than FTF education and were indifferent to the discipline in the learning environments. A slightly significant difference existed for time investment as both groups felt that FTF required more time investment. Interestingly, both groups were undecided as to the appropriateness of online education. In general, in the original survey students favored FTF education over online education. Furthermore, the original research showed that as students acquired more online experience, their perceptions of online education became more positive (Fish \& Snodgrass, 2014). Therefore, with an increase in the number of online courses and technology changes at the University, have the students' perceptions changed?

Student perceptions regarding the online learning experience should be realistic (Tanner, Noser \& Totaro, 2009). Theoretically, the more someone is exposed to and uses a particular technology or method, the more adept they become (Tanner et al., 2003; Tekinarslan, 2011; Dobbs et al., 2009). As shown in the original study, students' acceptance of online education may increase as the number of online courses they take increases (Fish \& Snodgrass, 2014). In a study performed over a decade ago, as course activities and student interactions with others were satisfied, students' perceptions changed (Mortagy \& Boghikian-Whitby, 2010). Another researcher also found that as students acquire more online experience, their perception of online courses improves (Tanner et al., 
2003). One researcher initially indicated that at least 5 online courses are necessary for students to perceive that they learn more in the online environment than FTF (Dobbs et al., 2009). Yet another survey found that graduates grew to accept online education as being equal to or better than traditional FTF education over time (Perrault et al., 2008).

We conducted the original study on student perceptions of online and FTF education in the fall of 2012. Since that time, the number of online courses increased at the University, and instructor methods to teach online and available technologies changed. In the original training for online instruction introduced instructors to available technology. The instructor makes all decisions regarding online course design as course designers do not exist at the University. Changes since the original study for online technology include a change to Desire2Learn at the University (from Angel), from face-to-face interaction through 'GoToMeeting' to Zoom, the increase in Youtube, Google, and other videos availability, and additional access to database management systems such as Python and ' $R$ '. The instructor decisions that are made in the delivery of an online and FTF course impact upon student perceptions. Barriers to distance education include: faculty, organization and course structure; physical distance; difficulties in dealing with media; time constraints; lack of background knowledge, distance education experience or technology skills; and low interactivity with the communication process (Olesova, Yang \& Richardson, 2011).

Student attitudes and perceptions are important antecedents of the student's inclination toward online learning (Chawla \& Joshi, 2012), and include motivation, belief, confidence, computer anxiety, fear, boredom, apprehension, enthusiasm, excitement, pride and embarrassment (Konradt \& Sulz, 2001). Student demographic characteristics - major, gender, age, undergraduate versus graduate, technology understanding, and previous experience with online education, may impact upon a student's perceptions of online education. In this paper, the changes from the original study for the individual student perceptions of motivation, 
discipline, self-directed, independence, schedule flexibility, time and cost investment, happiness and appropriateness of online education are studied. We continue with a discussion of various individual characteristics and their impact upon student perceptions of online education.

\section{Student Motivation, Discipline, Self-directed Learning and Inde-} pendence: In general, students are more motivated in courses when course content interests them and they find the material to be relevant (Adler et al., 2001). Prior research on student motivation in the online environment reveals mixed results. Some studies indicated that the online environment increases student motivation (Kearsley, 1996) or critical thinking and work motivation (Larson \& Sung, 2009). However, other studies indicate that the online environment offers low motivation for students to learn (Maltby \& Whittle, 2000) with retention issues (Abouchedid \& Eid, 2004; Carr, 2000;) and low student satisfaction (Kenny, 2003; Muilenburg \& Berge, 2005). Yet another study indicates that students view online learning as a commitment (Chawla \& Joshi, 2012). Students that are not self-motivated and committed will not enjoy the online learning environment (Rivera \& Rice, 2002) as online students should be motivated and disciplined (Schott et al., 2003). Culture may be an important factor in motivation as individualistic students are more motivated to participate in online learning then collectivistic students (Tapanes et al., 2009). Online learning requires self-directed learning and autonomy, but self-discipline and motivation are required to complete the course (Gifford, 1998; Kearsley, 2002). Good time management skills and self-discipline are student attributes that are required in online learning (Cheung \& Kan, 2002). Saudi Arabian women experienced an increase in independence through online education as they had greater control over the learning process and discussed points of view and experienced different ways of thinking, different styles of writing and different approaches to improving their communication skills (Hamdan, 2014). Regardless of the environment, some students regard collaborative learning negatively and always prefer to work independently (Hiltz \& Turoff, 2005). Students' desires to work independently versus collectively 
differ by cultures as shown by a study comparing U.S. students who preferred independent work to Chinese students, who preferred group work (Lin et al., 2010).

In the original 2012 study, motivation, self-directed, and independence were all significant factors as the online and FTF students were more motivated and preferred the self-directed learning of the FTF environment. Online students preferred the independence online over FTF, while FTF students were relatively indifferent to the independence in the learning environments. In the original study, students did not perceive the discipline required to be different between the two environments. Therefore, we pose the following research question: Over the past 6 years, have students' perceptions of the motivation, discipline, self-directed nature or independence required online versus FTF changed?

Schedule Flexibility: Students often cite convenience and flexibility as relevant factors for choosing an online course (Fish \& Snodgrass, 2014; Horspool \& Lange, 2012; Perreault et al., 2008). In the original 2012 study, students perceived the schedule flexibility to be more in the online environment than the FTF one (Fish \& Snodgrass, 2014). Therefore, we pose the following research question: Over the past 6 years, have students' perception of schedule flexibility online versus FTF changed?

Time and Cost Investment: While students perceive online courses to have time flexibility to take the course (Chawla \& Joshi, 2012; Grandon et al., 2005), they perceive online learning to be more time consuming (Gifford, 1998; Perreault et al, 2008: Dobbs et al., 2009). In one study, students who had never taken an online course indicated that they felt the value from an online course would be less than FTF (Chawla \& Joshi, 2012). In the original 2012 study, online and FTF students favored the FTF environment for both time and cost investment. Therefore, we pose the following research question: Over the past 6 years, have students' perception of time investment and cost investment online versus FTF changed?

Happiness and Appropriateness for Learning Environment: Clearly from the discussion above, ambiguity currently exists in the 
debate between online and FTF education. Student satisfaction research with online versus FTF formats results are mixed as some studies indicate that the courses are equally effective across formats (Fowler, 2005; Topper, 2007; Horspool \& Lange, 2012), while others show a preference to FTF over online environments (Mullen \& Tallent-Runnels 2006), and others show a higher satisfaction for online learning (Connolly, MacArthur, Stansfield \& McLelan, 2007). One study conducted over a decade ago found that $10-20 \%$ of students always prefer FTF (Hiltz \& Turoff, 2005). In general, when students perceive online learning as useful, they are more likely to accept and learn online (Tung \& Chang, 2008). In the original 2012 study, FTF students were overwhelmingly positive to FTF education and online students also favored FTF education over online. Both groups were generally undecided about the appropriateness of online education at the University. Therefore, we pose the following research questions: Over the past 6 years, did student's perceptions of their happiness change? Over the past 6 years, have student's perception of the appropriateness of online learning at the University changed?

Salient Conclusions for Our Study. While not intended to be a comprehensive review of literature in this area, the literature presented here indicates that ambiguity currently exists in the debate between online and FTF education. Research results on student satisfaction with online versus FTF formats are mixed as some studies indicate that the courses are equally effective across formats (Fowler, 2005; Topper, 2007; Horspool \& Lange, 2012), while others show a preference to FTF over online environments (Mullen \& Tallent-Runnels 2006), and others show a higher satisfaction for online learning (Connolly, MacArthur, Stansfield \& McLellan, 2007). Studies differ in the audience (e.g. scientific versus social sciences, business versus non-business, and graduate versus undergraduate), size (small, medium, large universities), and method of research (e.g. interview, survey). Several online perception studies were completed at large universities or in a public forum (Tanner et al., 2003; Tanner et al., 2004-1; 2004-2; Tanner et al, 2006; Tanner et al., 2009) or in non-business fields (e.g. Dobbs et al., 2009; Lanier, 2006; Leasure et 


\section{The BRC Academy Journal of Education Vol. 8, No. 1}

al., 2000; Reilly et al., 2012; Tekinarslan, 2011; Wang \& Morgan, 2008). Thus, the study's context may be an important factor to consider. Most business student perceptions research was published over 10 years ago (e.g. Perreault et al., 2008; Tanner et al., 2003; Tanner et al., 2004-1, 2004-2), and similar to other studies (Mortagy \& Boghikian-Whitby, 2010; Perreault et al., 2008), perceptions may have changed. This study seeks to analyze whether changes in student perceptions on individual factors has occurred over 6 years. In general, for each of the individual student factors discussed above, this study seeks to analyze the following hypotheses:

$\mathrm{H}_{10 \mathrm{~A}}$ In the online environment, over the past 6 years, students' perceptions of online education versus FTF have remained the same.

$\mathrm{H}_{11 \mathrm{~A}}$ In the online environment, over the past 6 years, students' perceptions of online education versus FTF have changed.

$\mathrm{H}_{20 \mathrm{~B}}$ In the FTF environment, over the past 6 years, students' perceptions of online education versus FTF have remained the same.

$\mathrm{H}_{21 \mathrm{~B}}$ In the FTF environment, over the past 6 years, students' perceptions of online education versus FTF have changed.

We conducted our study at a mid-sized, Jesuit, Catholic, business school with a focus on teaching. The research focus lies in uncovering changes in student perceptions since our original study in 2012. Online courses typically have a maximum of 24 students and traditionally, FTF class sizes average 17 students. Online education is a growing educational method; however, not all students have experienced this medium (Allen \& Seaman, 2013). Based upon the literature, the research intent of this paper is to explore the changes in graduate and undergraduate students' perceptions of the online experience for those with and without online experience at a teaching university for individual factors. Specifically, we will address changes in student perceptions between the original 2012 study and now for individual factors of motivation, discipline, self-directed, 
independence, schedule flexibility, time and cost investment, happiness, and appropriateness of online education. Theoretically, students should perceive the environments equally and not favor either traditional or online education.

\section{METHOD}

Undergraduate and graduate business students at an AACSB accredited, Jesuit, Catholic University in the northeast completed an online Qualtricsadministered survey. Student participation was completed voluntary. Twice over the month of November, students received the survey link via a list serve. 60 graduates and 74 undergraduate students participated in the 2018 survey. In the fall of 2012, a similar survey was administered directly in class to students in FTF classes, and 64 undergraduate and 47 graduates participated (Fish \& Snodgrass, 2014).

\section{Limited Preview Complete}

This completes the limited preview of this paper. Please purchase full access.

\section{Citation Information}

Fish, Lynn A., and Coral R. Snograss. "A Preliminary Study of Changing Business Student Perceptions of Individual Factors in Online Versus Face-to-Face Education." The BRC Academy fournal of Education 8, no. 1 (2020): 61-83. https://dx.doi.org/10.15239/j.brcacadje.2020.08.01.ja03

\section{Web Appendix}

A web appendix for this paper is available at: https://dx.doi.org/10.15239/ j.brcacadje.2020.08.01.wa03 